\title{
MAINTAINING A COLD CHAIN IN RETAIL: DOES IT WORK?
}

\author{
Jevšnik, M., Ovca, A., Likar, K. \\ University of Ljubljana, College of Health Studies, Department of Sanitary Engineering, \\ Poljanska 26a, SI-1000 Ljubljana, Slovenia \\ E-mail: mojca.jevsnik@vsz.uni-lj.si, Tel. 003861 3001111,Fax 0038613001119
}

\begin{abstract}
A survey of the retail in Ljubljana, the capital city of Slovenia regarding the maintenance of a cold chain is presented now, when HACCP is mandatory for three years already (since January $1^{\text {st }} 2003$ ). The objectives were: to analyze the situation of maintaining a cold chain in retail and to find out handling of selected perishable foodstuffs in stores. We compared the results with the findings from our first research in this field in 2002 when HACCP was not yet mandatory. In both researches we confirmed that a cold chain is broken at retail. In the previous survey seventeen stores and in the current survey fifteen stores were divided in three groups, according to store surface: large, medium and small ones. The results of the researches in 2002 showed that the storage conditions were properly shown on the packages of the articles inspected. In most instances the temperatures measured differed from those required, even up to $10^{\circ} \mathrm{C}$. The greatest differences were detected between temperatures indicated in their cooling appliances and temperatures measured by our calibrated thermometers. Conditions during storage and retail of food were not documented and there were no systems to control the cold chain at that time. Findings of the research from 2002 have shown that retailers are not familiar with the importance of a cold chain. The results of the research in this year are described into details in the paper.
\end{abstract}

Key words: Cold chain, Food trade, Retail, Storage

\section{INTRODUCTION}

Food safety understanding is a concept, which begins with technologies and goes all the way to the legislation, from the producer to the consumer (Raspor, 2004). Eating outside home and usage of partly or fully cooked food is increasing. Tivadar (2003) cited that this is not result of its increasing popularity, but it is a reaction on special configuration of time problems, how to organize everyday life.

The principal objective of the new general and specific hygiene rules is to ensure a high level of consumer protection with regard to food safety. Food business operators shall ensure that all stages of production, processing and distribution of food under their control satisfy the relevant hygiene requirements laid down in Regulation (EC) No 852/2004. This regulation emphasizes the importance of cold chain throughout HACCP system for all foodstuffs that require cooling or freezing regime. In Slovenia a HACCP system is compulsory since January the 1 st 2003.

Kassianenko, Wszol, Oggel \& Jol (2006) emphasise the importance of cold chain, which is a vital part of modern global trade as it has impact on all food commodities. In today's modern society, refrigerated storage is one of the most widely practiced methods of preserving perishable foods. Improper use of this process increases the potential risk that microbial hazards will advance, thus leading to foodborne illness. 
Temperature is a key parameter ensuring food safety and wholesomeness. If the temperature and the environmental conditions meet requirements, we can slow down or totally inhibit microbial growth and the production of toxins. Refrigeration is present all along the food chain: more than $50 \%$ of foodstuffs in developed countries (1.2 billion inhabitants) are retailed under refrigerated conditions; one can speak of a cold chain from raw materials (post-harvest) to food on the table of the consumer. Food safety starts with the raw materials. However, it took about 30 years in most developed countries (1945-1975 in Europe for example) to set up reliable cold chains. In developing countries ( 5 billion inhabitants), only a small proportion of food is chilled or frozen (Billiard \& Viard, 2002).

Refrigerated foods are one of the fastest growing sectors of the grocery and foodservice industries. Continued success relies upon effective management of the cold chain, a term used to describe the series of interdependent operations in the production, distribution, storage and retailing of chilled and frozen foods. Control of the cold chain is vital to preserve the safety and quality of refrigerated foods and comply with legislative directives and industry »codes of practice« (Tom, 2006). In the distribution of chilled and frozen food, the cold chain, which starts at the plants cold store, includes the central and distribution cold stores and ends at cold stores in retail cabinets, plays a very important role for maintaining the food quality (Zhang, Habenicht, Spieß, 2003). In order to ensure product quality, the controlled temperatures throughout the cold chain are necessary. Therefore, the required temperature must be maintained from production to consumption (Moureh \& Derens, 2000). Temperature measurements of a perishable food show large variations of temperature after short exposure to ambient conditions. Moureh \& Derens (2000) cited authors who investigated logistic food chain showing that the temperature rise is a function of product properties, ambient conditions, the size and kind of packaging, the presence and thickness of air layer between the product and the package, solar exposure, and the use of insulating pallet covers.

Perishable and frozen foods require strict temperature control throughout the production to the consumption. Every unit of food chain has to maintain a cold chain and document storage conditions. Cortella (2002) and Foster et al. (2005) argue that open display cabinets are known to be the weakest link in the chilled food chain and, therefore, particular attention is paid to their design.

The objectives of our survey were to analyze the situation of maintaining a cold chain in retail and to find out handling of selected perishable foodstuffs in stores, regarding their size. We compared the results with the findings from our first pilot research in this field in 2002 (Likar \& Jevšnik, 2006) when HACCP was not yet mandatory.

\section{MATERIALS AND METHODS}

The survey was conducted in April and May 2006. Fifteen retail stores in Ljubljana and its surrounding area were divided into large (supermarkets), medium (self-service stores) and small ones (classical stores). We were interested if foodstuff handling differs between stores with different sales area size. According to legislation $\left(\right.$ Rules $\left.^{1}\right)$, stores are classified with regard to sales areas: classic stores (above $12 \mathrm{~m}^{2}$ ), self-service stores (above $40 \mathrm{~m}^{2}$ ) and supermarkets (above $1000 \mathrm{~m}^{2}$ ). We selected articles to be inspected by two criteria, by the short date of usability and by the conditions of storage temperature (storage at cooling or frozen conditions).

At the time of investigation the date of durability, labelling, and the handling of products (package condition) were controlled and storage conditions in cooling appliances for storage 
of eight selected perishable foodstuffs (pre-packaged poultry, pre-packaged frankfurters, butter, yoghurt, cottage cheese, cream, ice cream and eggs) were measured.

Five temperature readouts and measurements were checked and compared for evaluation of temperature conditions in cooling and refrigerating units:

- reading temperature required by producer $(\mathrm{P})$,

- reading temperatures shown on displays - air temperature display control (ATDC),

- reading temperatures shown on control thermometers placed in cooling appliances (refrigerators, freezers) - air temperature control (ATC),

- temperatures measured with a probe inserted between two samples of the same foodstuffs - surface foodstuffs temperature (SPT) and

- internal measured temperatures of one chosen product - yoghurt (IMT).

We choose eight foodstuffs according to their location in the cooling or refrigerating units, and measured their temperature. We were looking for critical parts in these units (e.g. icecream which was closest to the line marking the maximum filling level or products near neon lights). Readings and measurements were taken twice a day between 10.00 and 12.00 and again between 15.00 and 17.00 hours. These periods were chosen because the frequency of consumers is highest between those two peaks.

Temperatures were measured with our calibrated thermometer Testo177-T4 (Calibrated certificate No.147697, date 06.12.2005) and water-tight immersion/penetration probes (measurement range from -60 to $+400^{\circ} \mathrm{C}$ ).

\section{RESULTS AND DISCUSSION}

In fifteen retail stores, out of which five small, five medium and five large sized stores, 232 perishable foodstuffs were examined.

\section{Handling of perishable foods}

When checking the storage conditions we were also interested in type of cooling appliances used, hygiene, presence of ice crystals, presence of any items that could damage packing material, influence of lights and refilling procedure. We established that medium and large stores have better conditions for cooling and refrigerating foodstuffs compared to small stores, which have to deal with less space thus trying to put as much as possible into their units. These units are on average smaller and mostly overfilled which inhibits movement of cooled air around them. This very well known fact of thermodynamics is among very important recommendations for shops (Guide, 2005). Overfilling the cooling units also means that some products are too close to lights which warm them at least partially.

We often observed improper handling of ice-cream at all three groups of stores: a) refrigerating units are being filled over the maximum level (graded $C$ in Table 1) and b) auto-defrosting system is not working properly in some cabinets allowing ice crystals to form on the cabinets doors (graded B in Table 1). Some shops received grade B (Table 1), because visible particles of dirt was detected in their cooling or refrigerating units although this does not influence the quality of product (all products are pre-packed). Majority of middle sized shops received grade B. Grade C (Table 1) was given to units being overfilled with products which have also being placed too close to lights that warmed them up. This was the case at majority of small sized shops.

Checking the dates of durability has clearly became an important practice and is being carried out according to recommendations for retail (Guide, 2005) which depends on the 
longevity of individual products (long duration products $-2 \mathrm{x}$ monthly; short duration products $1 \mathrm{x}$ daily). Among all fifteen shops only one sample of pre-packaged poultry was found with expired date of durability (Table 1).

To determine the suitability of packing we inspected two important parameters: all products need to have undamaged packing and have to be equipped with a visible and clearly written declaration in Slovenian language (Table 1). Any special storage conditions or instructions for preparation should be included and are mandatory $\left(\right.$ Rules $\left.^{2}\right)$. We established that employees in all three groups of examined shops handle products with care. Declarations on all products meet above mentioned rules. We found two cases of damaged ice-cream packages in large stores and one damaged butter package in medium sized store. This results show that damaged package is a regular incident in large shops due to higher frequency of consumers and an insufficient level of control by the employees.

Table 1. Observation sheet for controlling the storage conditions, date of durability and labelling, and the handling of products (package condition) of eight selected perishable foodstuffs, regarding the size of store.

\begin{tabular}{|c|c|c|c|c|c|c|c|c|c|}
\hline \multirow[t]{2}{*}{ Type of store } & \multirow[t]{2}{*}{ Foodstuffs } & \multirow[t]{2}{*}{$\mathrm{N}^{1}$} & \multicolumn{3}{|c|}{$\begin{array}{c}\text { Storage } \\
\text { conditions }\end{array}$} & \multicolumn{2}{|c|}{$\begin{array}{c}\text { Date of } \\
\text { durability }^{3}\end{array}$} & \multicolumn{2}{|c|}{$\begin{array}{c}\text { Package } \\
\text { conditions }\end{array}$} \\
\hline & & & A & $\mathrm{B}$ & $\mathrm{C}$ & $\mathrm{S}$ & US & $\mathrm{S}$ & US \\
\hline \multirow[t]{8}{*}{ Large } & Pre-packaged poultry & \multirow{8}{*}{5} & 5 & 1 & 1 & 5 & I & 5 & I \\
\hline & Pre-packaged frankfurters & & 5 & 1 & 1 & 5 & 1 & 5 & 1 \\
\hline & Butter & & 5 & 1 & 1 & 5 & 1 & 5 & 1 \\
\hline & Yoghurt & & 5 & 1 & 1 & 5 & 1 & 5 & 1 \\
\hline & Cottage cheese & & 5 & 1 & 1 & 5 & 1 & 5 & 1 \\
\hline & Cream & & 5 & 1 & 1 & 5 & 1 & 5 & 1 \\
\hline & Ice cream & & 2 & 1 & 2 & 5 & 1 & 3 & 2 \\
\hline & Eggs & & $5 *$ & 1 & 1 & 5 & 1 & 5 & 1 \\
\hline \multirow[t]{8}{*}{ Medium } & Pre-packaged poultry & \multirow{8}{*}{5} & 5 & 1 & 1 & 5 & 1 & 5 & 1 \\
\hline & Pre-packaged frankfurters & & 5 & 1 & 1 & 5 & 1 & 5 & 1 \\
\hline & Butter & & 3 & 2 & I & 5 & 1 & 4 & 1 \\
\hline & Yoghurt & & 5 & 1 & 1 & 5 & 1 & 5 & 1 \\
\hline & Cottage cheese & & 4 & 1 & 1 & 5 & 1 & 5 & 1 \\
\hline & Cream & & 5 & 1 & 1 & 5 & I & 5 & 1 \\
\hline & Ice cream & & 3 & 2 & 1 & 5 & 1 & 5 & 1 \\
\hline & Eggs & & 4 & 1 & 1 & 5 & 1 & 5 & 1 \\
\hline \multirow[t]{8}{*}{ Small } & Pre-packaged poultry & \multirow{8}{*}{5} & 5 & 1 & 1 & 4 & 1 & 5 & 1 \\
\hline & Pre-packaged frankfurters & & 3 & 1 & 1 & 5 & 1 & 5 & 1 \\
\hline & Butter & & 4 & 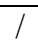 & 1 & 5 & 1 & 5 & 1 \\
\hline & Yoghurt & & 4 & 1 & 1 & 5 & 1 & 5 & 1 \\
\hline & Cottage cheese & & 4 & 1 & 1 & 5 & 1 & 5 & 1 \\
\hline & Cream & & 5 & 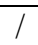 & 1 & 5 & 1 & 5 & 1 \\
\hline & Ice cream & & 3 & 1 & 1 & 5 & 1 & 5 & I \\
\hline & Eggs & & 4 & 1 & 1 & 5 & 1 & 5 & 1 \\
\hline
\end{tabular}

Legend:

${ }^{1} \mathrm{~N}$ : number of examined samples of individual foodstuffs, regarding of the store.

${ }^{2}$ Storage conditions: A (no visible dirt; no ice crystals on cabinets doors; no items causing damage to package; no influence by the heat from the lights; optimal filling), B (presence of items which does not cause any damage to packing; formation of ice on cabinets doors; overfilling on a certain spot), C (visible dirt; ice on cabinets doors; presence of items causing damage to packing; products being filled too close to lights; overfilling - above the maximum level).

${ }^{3}$ Date of durability: S- suitable; US-unsuitable

${ }^{4}$ Package conditions: S- suitable; US-unsuitable

*Eggs were not in the refrigerator. 


\section{Storage conditions}

According to regulation for safety of frozen foodstuffs (Rules ${ }^{3}$ ) the temperature of any frozen product has to be stable and should be maintained at $-18^{\circ} \mathrm{C}$ or lower, with short oscillations up to $3^{\circ} \mathrm{C}$ during transport, in food industry and retail stores. Maintaining the principles of good practice is very important during transport and retail. Recommendations for retail stores (Guide, 2005) emphasize the importance of keeping the cold chain continuous with exception of short interruptions. These interruptions are often inevitable (preparation, transport, storage, selling process) but the limit of oscillation $\left(3^{\circ} \mathrm{C}\right.$ above recommended level) has to be respected by all means.

Results in Table 2 show that readouts from display (ADTC) on cooling or refrigeration units are mostly lower than average internal product temperature (IMT). We also established that in some cases ATDC temperatures are higher than average surface foodstuffs temperature (SPT) (e.g. frankfurters in large stores). We noticed severe oscillation of ADTC (from 2 to $3^{\circ} \mathrm{C}$ in one minute). Average ATDC values are not higher then temperatures required by producer (P) by any of foodstuffs. Average ATC values are higher then those required by producer for pre-packaged poultry and pre-packaged frankfurters (small and medium stores) and for yoghurt (small stores). The highest deviation of SPT values in comparison with P temperatures was found for cottage cheese (medium stores). Results in Table 2 show that average ATDC and ATC values are generally lower then average SPT values.

Checking control thermometers in cooling appliances it was found out that the retailers (especially in large shops) control the temperature in their cooling appliances only by reading temperature on open cabinets displays. Such temperature monitoring can oscillate and is therefore unreliable, misleading and is not reflecting the actual air temperature in cooling appliances. In some shops control thermometers are used only in older types of cooling appliances that are not equipped with displays. On the other hand there are exceptions mainly among middle sized shops that keep more thermometers in one single cooling appliance. But the number of thermometers does not contribute to the quality of measurement if they are placed randomly. Retailers also report that sometimes thermometers are stolen by consumers. To get realistic data on air temperature in cooling appliances, control thermometers have to be placed on various shelves at various high levels and places to find out the warmest points within cooling appliances. Foster et al. (2005) alleged that large $(>5 \mathrm{~K})$ temperature differences in most cabinets is due to the technical difficulties in reducing the difference between the lowest temperature packs, which are usually sited at the rear of the cabinet and the highest temperature packs, sited at the front of the cabinet.

Average SPT values show that temperature requirements are met mostly by large shops. This holds for all chosen products accept for ice-cream. In our opinion this is affected by the age of cooling appliances (newer being better) and the volume of open cabinets (the larger can offer a greater variance of different kinds of foodstuffs). Better results of average SPT for ice-cream were found in small shops, which were equipped with older cooling appliances. These are closed cabinets (cabinets with glass or plastic lids). Newer ones on the other hand are kept open to attract consumers' attention, but do not kept frozen foodstuffs at the temperature declared by producers.

Maximal SPT values among all analyzed foodstuffs exceed the temperature declared by producers. In most cases they also exceed short-term allowed deviations (from retail guidelines) - up to $3^{\circ} \mathrm{C}$. Among all checked products (in all shops), maximum SPT within allowed short-term deviation rate was found only for cream. There are several reasons for temperature oscillation between minimum and maximum values: automatic programming of cabinets (auto-defrosting twice a day), the rise of temperature during the day due to the influence of neon lights and costumers standing nearby, interruptions of cold chain caused 
by refilling of cabinets. If products are left for some time at room temperature, their temperature rises and consequently the temperature of other foodstuffs in the cooling appliance also rises. Morning temperature checking showed better results than afternoon values, because cabinets are closed during the night. Retailer recommendations (Guide, 2005) say that temperature measurements done one hour after opening the cabinets or autodefrosting are not adequate. Retailer should place foodstuffs requiring cold chain in cooling appliances no later than 20 minutes after their receipt. As a rule the required cold chain should not be disconnected with the exception of short-term interruptions (Guide, 2005).

Table 2. Differences in large, medium and small sized stores between the lowest, the highest and average values for ATDC, ATC, SPT, IMT in comparison with foodstuffs storage temperature required by producer.

\begin{tabular}{|c|c|c|c|c|c|c|c|c|c|c|c|c|c|c|}
\hline \multirow[t]{2}{*}{ Foodstuffs } & \multirow[t]{2}{*}{$\begin{array}{l}\text { Size of } \\
\text { store }\end{array}$} & \multirow[t]{2}{*}{$\begin{array}{l}\mathrm{P}^{1} \\
\left({ }^{\circ} \mathrm{C}\right)\end{array}$} & \multicolumn{3}{|c|}{$\begin{array}{c}\text { ATDC }^{2} \\
\left({ }^{\circ} \mathrm{C}\right)\end{array}$} & \multicolumn{3}{|c|}{$\begin{array}{c}\text { ATC }^{3} \\
\left({ }^{\circ} \mathrm{C}\right)\end{array}$} & \multicolumn{3}{|c|}{$\begin{array}{l}\mathrm{SPT}^{4} \\
\left({ }^{\circ} \mathrm{C}\right)\end{array}$} & \multicolumn{3}{|c|}{$\begin{array}{l}\text { IMT }^{5} \\
\left({ }^{\circ} \mathrm{C}\right)\end{array}$} \\
\hline & & & $\operatorname{Min}^{6}$ & $\operatorname{Max}^{7}$ & $x^{8}$ & $\operatorname{Min}^{6}$ & $\operatorname{Max}^{7}$ & $x^{8}$ & $\operatorname{Min}^{6}$ & $\operatorname{Max}^{7}$ & $x^{8}$ & $\operatorname{Min}^{6}$ & $\operatorname{Max}^{7}$ & $x^{8}$ \\
\hline \multirow{3}{*}{$\begin{array}{l}\text { Pre- } \\
\text { packaged } \\
\text { poultry }\end{array}$} & Small & -2 to & 0 & 5.0 & 2.9 & 3.0 & 7.5 & 5.3 & 5.1 & 10.1 & 7.9 & & & \\
\hline & Medium & +4 & 1.1 & 4.0 & 2.6 & 6.0 & 7.0 & 6.5 & 4.4 & 10.0 & 6.3 & & & \\
\hline & Large & & 0.9 & 6.0 & 2.8 & -1.0 & 5.0 & 2.3 & 3.3 & 7.8 & 5.1 & & & \\
\hline \multirow{3}{*}{$\begin{array}{l}\text { Pre- } \\
\text { packaged } \\
\text { frankfurters }\end{array}$} & Small & 0 to & 1.0 & 5.0 & 2.6 & 3.0 & 7.5 & 5.3 & 3.8 & 13.5 & 7.2 & & & \\
\hline & Medium & +4 & 1.7 & 6.0 & 3.8 & 4.0 & 7.0 & 4.6 & 5.9 & 13.7 & 8.7 & & & \\
\hline & Large & & 3.6 & 9.5 & 5.7 & 0 & 5.0 & 1.6 & 2.4 & 8.5 & 5.8 & & & \\
\hline \multirow[t]{3}{*}{ Butter } & Small & to +8 & 2.0 & 5.0 & 3.9 & 6.0 & 10.0 & 7.5 & 4.1 & 9.3 & 6.5 & & & \\
\hline & Medium & & -1.3 & 12 & 4.2 & 1.0 & 11.0 & 5.8 & 5.5 & 17.5 & 10.4 & & & \\
\hline & Large & & 3.8 & 6.2 & 4.5 & 8.0 & 8.0 & 8.0 & 0.8 & 11.9 & 5.8 & & & \\
\hline \multirow[t]{3}{*}{ Yoghurt } & Small & 0 to & 0 & 5.0 & 4.1 & 6.0 & 12.0 & 8.2 & & & & 4.5 & 10.6 & 7.2 \\
\hline & Medium & +8 & -0.5 & 7.0 & 2.6 & 2.0 & 6.0 & 4.7 & & & & 5.0 & 12.7 & 7.8 \\
\hline & Large & & 2.7 & 9.6 & 6.5 & 4.0 & 4.0 & 4.0 & & & & 2.5 & 9.2 & 5.5 \\
\hline \multirow{3}{*}{$\begin{array}{l}\text { Cottage } \\
\text { cheese }\end{array}$} & Small & +2 to & 1.0 & 5.0 & 3.2 & 4.0 & 13.0 & 6.4 & 5.4 & 11.9 & 8.6 & & & \\
\hline & Medium & +8 & 0.9 & 5.1 & 3.8 & 2.0 & 6.0 & 4.6 & 4.7 & 13.5 & 12.4 & & & \\
\hline & Large & & 1.5 & 6.0 & 3.8 & 8.0 & 8.0 & 8.0 & 3.8 & 10.0 & 7.2 & & & \\
\hline \multirow[t]{3}{*}{ Cream } & Small & 0 to & 2.2 & 5.0 & 3.9 & 5.0 & 13.0 & 7.2 & 5.1 & 10.9 & 7.1 & & & \\
\hline & Medium & +8 & 1.1 & 5.4 & 3.9 & 2.0 & 6.0 & 4.1 & 6.5 & 9.9 & 7.8 & & & \\
\hline & Large & & 3.0 & 7.2 & 4.8 & 3.0 & 8.0 & 5.5 & 1.8 & 10.3 & 6.3 & & & \\
\hline \multirow[t]{3}{*}{ Ice cream } & Small & Les & -36.0 & -18.0 & -27.0 & -33.0 & -18.0 & -23.1 & -27.8 & -13.1 & -19.0 & & & \\
\hline & Medium & than & -24.0 & -16.0 & -20.1 & -21.0 & -20.0 & -20.5 & -23.6 & -8.4 & -15.8 & & & \\
\hline & Large & -18 & -25.8 & -11.9 & -19.9 & -20.0 & -20.0 & -20.0 & -23.7 & -5.1 & -14.4 & & & \\
\hline \multirow[t]{3}{*}{ Eggs } & Small & Keep & 1.0 & 8.0 & 5.0 & 2.0 & 12.0 & 6.1 & 6.6 & 12.9 & 9.2 & & & \\
\hline & Medium & on & 3.0 & 12.0 & 4.9 & 3.0 & 11.0 & 7.1 & 5.2 & 12.4 & 7.5 & & & \\
\hline & Large & cold & 3.5 & 6.2 & 4.4 & 8.0 & 8.0 & 8.0 & 3.3 & 11.9 & 7.1 & & & \\
\hline
\end{tabular}

Legend:

${ }^{1}$ Reading temperature $\left({ }^{\circ} \mathrm{C}\right)$ required by producer $(\mathrm{P})$

2 Reading temperatures $\left({ }^{\circ} \mathrm{C}\right)$ shown on displays - air temperature display control (ATDC)

${ }^{3}$ Reading temperatures $\left({ }^{\circ} \mathrm{C}\right)$ shown on control thermometers placed in cooling appliances (refrigerators, freezers) - air temperature control (ATC)

${ }^{4}$ Temperatures $\left({ }^{\circ} \mathrm{C}\right)$ measured with a probe inserted between two samples of the same foodstuffs - surface foodstuffs temperature (SPT)

${ }^{5}$ Internal measured temperatures $\left({ }^{\circ} \mathrm{C}\right)$ of one chosen product - yoghurt (IMT)

${ }^{6} \mathrm{Min}$ - the lowest value $\left({ }^{\circ} \mathrm{C}\right)$

${ }_{8}^{7} \mathrm{Max}$ - the highest value $\left({ }^{\circ} \mathrm{C}\right)$

${ }^{8} \mathrm{x}$ - average value $\left({ }^{\circ} \mathrm{C}\right)$

Afternoon average SPT values (Fig. 1) were $0.5^{\circ} \mathrm{C}$ higher than in the morning. Storage temperatures required by producer were exceeded for pre-packaged poultry and prepackaged frankfurters (in all three types of store in the morning and in the afternoon), butter 
(medium stores, in the morning and in the afternoon), yoghurt (medium stores, in the afternoon), cottage cheese (medium stores, in the morning and in the afternoon), cream (medium stores, in the morning) and ice-cream (medium and large stores, in the morning and in the afternoon). But, there are all values except for pre-packaged poultry (small stores, in the morning and in the afternoon), pre-packaged frankfurters (medium stores, in the morning and in the afternoon) and ice-cream (medium and large stores in the morning) under allowed $3^{\circ} \mathrm{C}$ resignation.

Comparison between average morning and afternoon SPT values show lower values in the morning except for eggs in small shops and cream in medium size stores. Higher afternoon SPT temperatures could be a result of improper shifting of foodstuffs within the cabinets by employees and consumers.

Comparison of the avarage values of SPT and IMT (exclusively for yoghurt) in the morning and in the afternoon

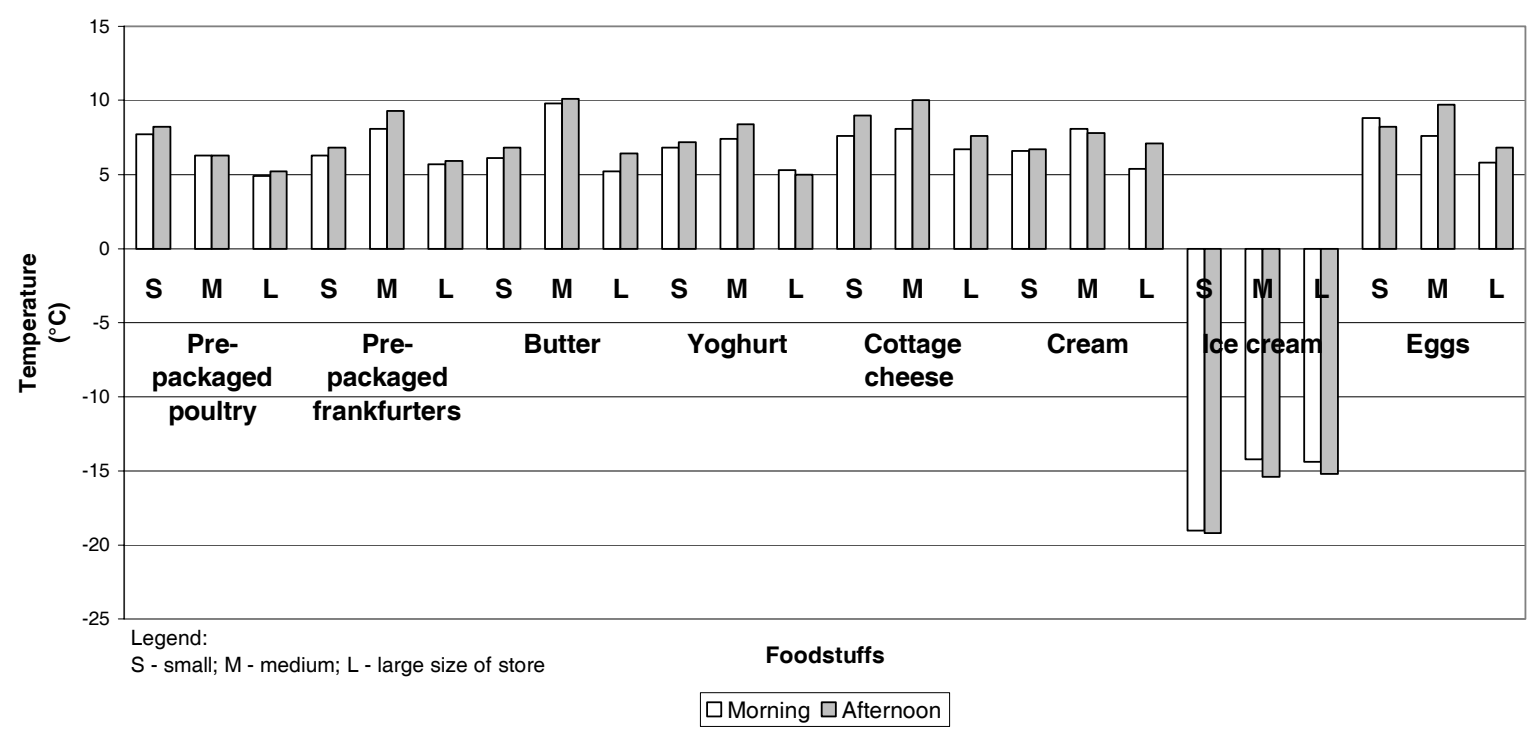

Fig.1. Comparison of morning and afternoon average SPT values (for seven selected foodstuffs except yoghurt) and IMT (for yoghurt), regarding the type of the retail.

Average ATDC values (Table 3) are higher then $\mathrm{P}$ only for pre-packaged frankfurters in large stores (in the morning and in the afternoon). Average ATC values (Table 3 ) are higher then $\mathrm{P}$ for pre-packaged poultry in small and medium size stores (in the morning and in the afternoon), pre-packaged frankfurters in small and medium size stores (in the morning and in the afternoon), yoghurt in small stores (in the afternoon) and cream in small stores (in the afternoon). 
Table 3. Comparison of morning and afternoon average ATDC, ATC, SPT values (for seven selected foodstuffs except yoghurt) and average IMT values (for yoghurt), regarding the type of the retail.

\begin{tabular}{|l|c|cc|ccc|cc|}
\hline \multicolumn{1}{|c|}{ Foodstuffs } & Size of & \multicolumn{2}{c|}{$\mathrm{x}$ ATDC $\left({ }^{\circ} \mathrm{C}\right)$} & \multicolumn{2}{c|}{$\mathrm{x}$ ATC ${ }^{\circ}\left({ }^{\circ} \mathrm{C}\right)$} & \multicolumn{2}{c|}{$\mathrm{x} \mathrm{SPT}^{3}\left({ }^{\circ} \mathrm{C}\right)$} \\
\cline { 2 - 8 } & store & Morning & Afternoon & Morning & Afternoon & Morning & Afternoon \\
\hline Pre-packaged & Small & 2.0 & 3.6 & 6.5 & 4.5 & 7.7 & 8.2 \\
poultry & Medium & 2.6 & 2.7 & 7.0 & 6.0 & 6.3 & 6.3 \\
& Large & 2.9 & 2.6 & 3.0 & 2.0 & 4.9 & 5.2 \\
\hline Pre-packaged & Small & 2.6 & 2.6 & 6.5 & 4.5 & 6.3 & 6.8 \\
frankfurters & Medium & 3.9 & 3.7 & 5.5 & 6.0 & 8.1 & 9.3 \\
& Large & 5.2 & 6.1 & 0 & 2.5 & 5.7 & 5.9 \\
\hline Butter & Small & 4.1 & 3.6 & 6.0 & 7.0 & 6.1 & 6.8 \\
& Medium & 3.9 & 4.6 & 4.6 & 6.3 & 9.8 & 10.1 \\
& Large & 4.2 & 4.7 & $/$ & 8.0 & 5.2 & 6.4 \\
\hline Yoghurt & Small & 3.1 & 3.1 & 6.5 & 8.7 & $6.8^{*}$ & $7.2 *$ \\
& Medium & 2.3 & 1.2 & 4.7 & 4.7 & $7.4^{*}$ & $8.4 *$ \\
& Large & 6.5 & 6.6 & $/$ & 4.0 & $5.3 *$ & $5.0^{*}$ \\
\hline Cottage cheese & Small & 3.5 & 3.0 & 5.5 & 7.0 & 7.6 & 9.0 \\
& Medium & 4.3 & 3.3 & 4.2 & 5.0 & 8.1 & 10.0 \\
& Large & 3.8 & 3.8 & $/$ & 8.0 & 6.7 & 7.6 \\
\hline Cream & Small & 4.3 & 3.5 & 5.5 & 9.0 & 6.6 & 6.7 \\
& Medium & 4.4 & 3.3 & 4.2 & 4.0 & 8.1 & 7.8 \\
& Large & 4.9 & 4.6 & $/$ & 5.5 & 5.4 & 7.1 \\
\hline Ice cream & Small & -26.0 & -28.0 & -24.0 & -22.0 & -19.0 & -19.2 \\
& Medium & -19.3 & -20.7 & -20.0 & -21.0 & -14.2 & -15.4 \\
& Large & -19.3 & -20.4 & $/$ & -20.0 & -14.4 & -15.2 \\
\hline Eggs & Small & 5.2 & 3.7 & 7.6 & 5.0 & 8.8 & 8.2 \\
& Medium & 3.8 & 6.0 & 5.3 & 8.3 & 7.6 & 9.7 \\
& Large & 4.1 & 4.7 & $/$ & 8.0 & 5.8 & 6.8 \\
\hline
\end{tabular}

Legend:

${ }^{1}$ Reading temperatures $\left({ }^{\circ} \mathrm{C}\right)$ shown on displays - air temperature display control (ATDC).

${ }^{2}$ Reading temperatures $\left({ }^{\circ} \mathrm{C}\right)$ shown on control thermometers placed in cooling appliances (refrigerators, freezers) - air temperature control (ATC).

${ }^{3}$ Temperatures $\left({ }^{\circ} \mathrm{C}\right)$ measured with a probe inserted between two samples of the same foodstuffs - surface foodstuffs temperature (SPT).

* Internal measured temperatures $\left({ }^{\circ} \mathrm{C}\right)$ of one chosen product - yoghurt (IMT).

\section{Comparison of the results of previous and recent surveys}

Our first pilot survey in this field named 'Cold chain maintaining in retail' was performed in 2002 (Likar \& Jevšnik, 2006) when HACCP was not mandatory. The results of the researches in 2002 showed that the storage conditions were properly shown on the packages of the articles inspected. In most instances the temperatures measured differed from those required, even up to $10^{\circ} \mathrm{C}$. The greatest differences were detected between temperatures indicated in their cooling appliances and temperatures measured by our calibrated thermometers. Conditions during storage and retail of food were not documented and there were no systems to control the cold chain at that time. Findings of the research from 2002 have shown that retailers are not familiar with the importance of a cold chain.

The results of ATDC and SPT values were compared for seven foodstuffs in previous and recent surveys (Fig. 2). Yoghurt was excluded from the comparison because of the different approach of measuring in 2002 (when the surface temperatures were measured) and 2006 (when the internal temperatures were measured). Comparison of average ATDC values and 
average SPT values has shown, somewhat worse results now, when HACCP is mandatory for three years already. SPT of seven selected foodstuffs were in average higher for $2.6^{\circ} \mathrm{C}$ in comparison with survey in 2002. However exceeded SPT values were found out also in 2002 for pre-packaged poultry and pre-packaged frankfurters in medium size stores. Comparison of maximum SPT values revealed a $2.9^{\circ} \mathrm{C}$ higher temperature in 2006 survey. Average ATDC values from 2006 survey are in average higher for $2^{\circ} \mathrm{C}$ in comparison with 2002 survey. Higher average ATDC values in current survey are due to the higher minimal ATDC values (comparison of maximum values showed an average difference of $0.7^{\circ} \mathrm{C}$ only).

Comparison of the avarage SPT values between two surveys

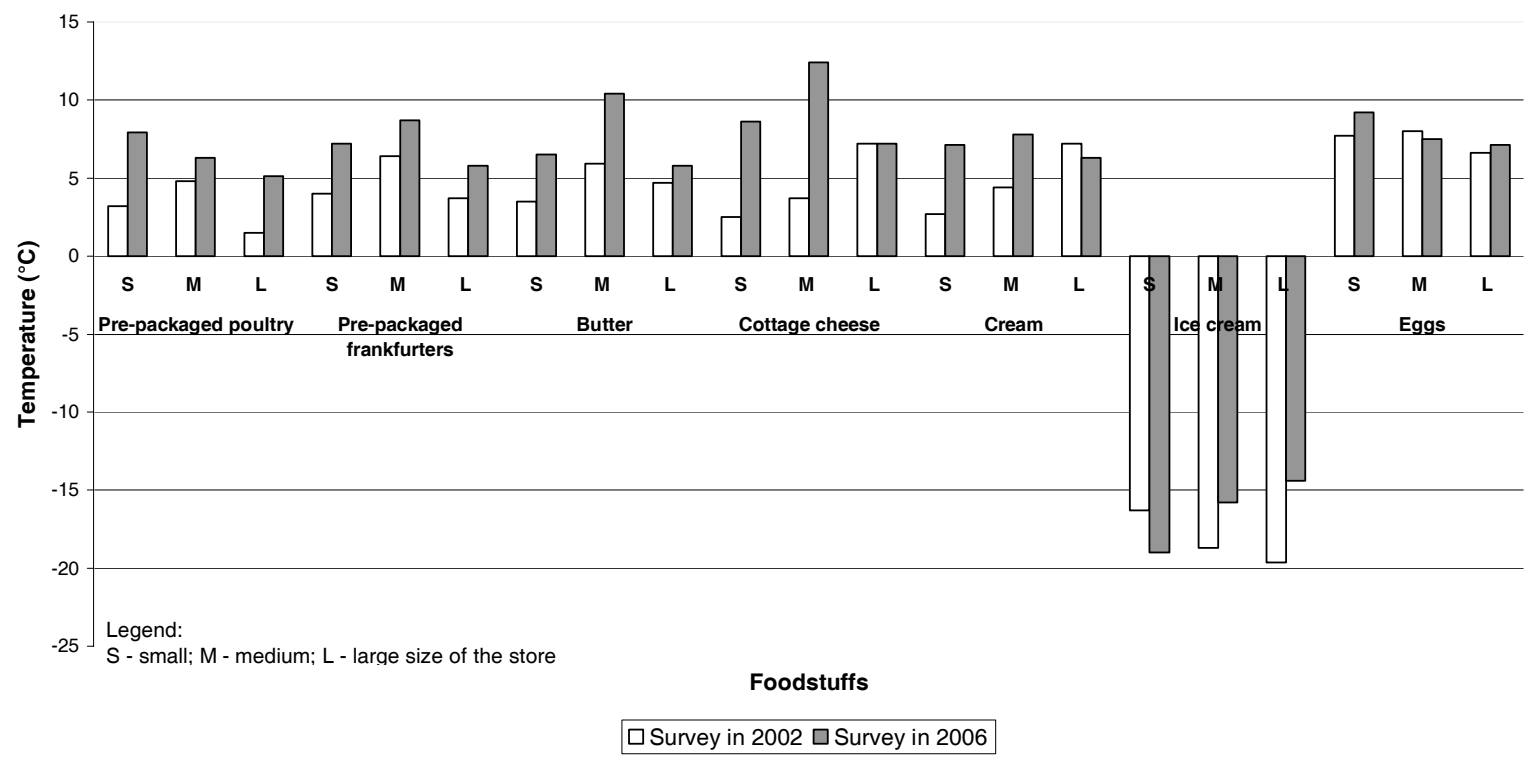

Fig. 2. Comparison of the average SPT values (for seven selected foodstuffs except yoghurt) between surveys in 2002 and 2006, regarding the type of the retail.

Comparing the survey in 2002, when we have ascertained that control system of cold chain was far from successful implementation, we now discovered that appropriate records documenting control of temperatures in cooling and refrigerating appliances have been established. The only question that could arise is: "Are these results accurate enough and is the maintenance of existing cooling and refrigerating appliances properly implemented?".

\section{CONCLUSION}

Overview of maintaining a cold chain in three different-sized shops shows deviations are still present:

- breaking the cold chain from the side of shop assistants (products that require strict cold chain maintaining can frequently be exposed to higher temperatures than required by producer);

- a raise in temperature due to a specific way of working of refrigerators and freezers (auto-defrost two times a day); 
- supervision system of cool air temperature in cooling units is not always reliable (temperature oscillation on displays and improper setting of control thermometers in cooling units).

We established that cold chain is broken in the retail due to bad organisation of work process and inadequate supervision of employees. We can conclude that shop assistants interpreted 'bonus' of short-term allowed oscillation (up to $3^{\circ} \mathrm{C}$ ) to their favour. They accepted the oscillation as a rule and took responsibility for the product safety. However, following allowed oscillation they affect date of durability set by manufacturer that does not predict any temperature oscillation. Confrontation of manufacturer and shop assistant would therefore be of great importance - the aim of both being maintaining food safety for a consumer. For effective cold chain maintaining in shops it is essential to be familiar with cooling and freezing units. Data on temperature regimes of a particular cooling unit has to be requested from the manufacturer by the shop assistant. Then, latter has to decide where to store foodstuffs, according to their temperature declaration and temperature regime of the cooling unit. Carefully planned and efficiently provided education of employees is of great importance. Lectures should be carried out by competent experts with relevant experience, who will provide specific information to every employee according to their assigned task. Employees should be personally responsible for their work. Last, but not least, consumers should also be taken into account as they can also break the cold chain. Shop assistants as well as Slovene Consumers' Association are the ones responsible for informing consumers and making sure that the quality and safety of foodstuffs from the shop to the home is not compromised.

\section{ACKNOWLEDGMENT}

This study was supported by the College of Health Studies in Ljubljana. The authors are grateful to the participating stores.

\section{REFERENCES}

Billiard F., Viard D. 2002. Food Safety and Refrigeration. FAO/WHO Global Forum of Food Safety Regulators Marrakech, Morocco, 28 - 30 January 2002, Available on: http://www.fao.org/DOCREP/MEETING/004/AB435E.HTM (16.06.2006).

Cortella G. 2002. CFD-aided retail cabinets design. Computers and Electronics in Agriculture, 34: 43-66.

Likar K., Jevšnik M. 2006. Cold chain maintaining in food trade. Food Control, 17: 108-113.

Foster A. M., Madge M., Evans J. A. 2005. the use of CDF to improve the performance of a chilled multi-deck retail displey cabinet. International Journal of Refrigeration, 28: 698705.

Kassianenko A., Wszol K., Oggel J., Jol S. 2006. The Cold Chain, One Link in Canada's Food Safety Initiatives. Food Control (review copy for Food Control - Revised Document).

Guide to good hygiene practice and HACCP implementation in trade sector. 2005. Koci B. (Ed.), Lapornik M. (Ed.), Ministry of the Economy, 66p.

Moureh J., Derens E. 2000. Numerical modelling of the temperature increase in frozen food packaged in pallets in the distribution chain. International Journal of Refrigeration, 23: 540-552. 
Raspor P. 2004. Current viewpoint on food safety, p.1-14. In: Gašperlin L. (Ed.), Žlender B. (Ed.), Food safety, 22nd Food Technology Days dedicated to prof. F. Bitenc, 18. and 19. March 2004, Radenci. Biotechnical Faculty, Ljubljana, Slovenia.

Regulation (EC) No 852/2004 of the European Parliament and of the Council of 29 April 2004 on the hygiene of foodstuffs. Official Journal of the European Communities. L $226 / 3$.

Rules $^{1}$ on the minimum technical and other requirements for business premises intended for negotiating contracts, and conditions for negotiating contracts away from selling premises. Official Gazette of Republic of Slovenia No. 28/1993, 34/1993, 57/1993.

Rules $^{2}$ on the general labelling of pre-packaged foodstuffs. Official Gazette of Republic of Slovenia No. 50/2004 (58/2004, 43/2005, 64/2005, 83/2005, 115/2005).

Rules $^{3}$ on frozen foodstuffs safety. Official Gazette of Republic of Slovenia No. 63/2002, $117 / 2002,46 / 2006$.

Tivadar B. 2003. Save money, waste love: ambivalence toward purchased convenience food. Annales, Series Historia et Sociologia, 13(1): 87-102.

Tom P. D. (Web Ed.) 2006. Managing the cold chain for quality and safety. In: Seafood Network Information Center. Available on: http://seafood.ucdavis.edu/pubs/coldchain.doc (16.06.2006).

Zhang G., Habenicht W, Spieß W. E. L. 2003. Improving the structure of deep frozen and chilled food chain with tabu search procedure. Journal of Food Engineering, 60: 67-79 